\title{
Exploration and Detection of Quantitative Analysis Method of OPEs in Urine
}

\author{
Jun Chena ${ }^{a}$, Hongling Yin ${ }^{b}$, Lin Luoc, Fei Peng ${ }^{d}$, Yi Luo ${ }^{e}$, Xu Deng ${ }^{\dagger}$ \\ College of Resources and Environment, Chengdu University of Information Technology, Chengdu \\ 610225, China
}

\author{
a296460271@qq.com, byhl@cuit.edu.cn, c1103945660@qq.com, d346291815@qq.com, \\ e1317515510@qq.com, ${ }^{f} 1043691496 @$ qq.com
}

Keywords: organic phosphate; flame retardant; urine

Abstract. The quantitative determination method of seven organic phosphate esters (OPEs) in urine by gas chromatography-mass spectrometry was established and optimized by changing the derivative reaction procedure, the different sample doses and the different extraction reagents. The results showed that the best recovery ratio was obtained by filtration, HC-C18 column separation and purification, ethyl acetate: acetone ( $\mathrm{V}: \mathrm{V}=3: 2)$ elution and GC-MS determination process. The concentrations of 7OPEs in human urine were in the range of $44.41 \mathrm{ng} / \mathrm{L} \sim 644.73 \mathrm{ng} / \mathrm{L}$. This method is feasible. Different socio-economic development levels led to significant differences of the sources and degrees of OPEs pollution in human urine.

\section{Introduction}

As an excellent substitute for brominated flame retardants, organic phosphorus esters (OPEs) has been developed rapidly because of the brominated flame retardants being gradually phased out from the market worldwide ${ }^{[1]}$. Similar to brominated flame retardants, OPEs can also be released to the surrounding environment in the process of production and use, and has a certain environmental retention, and may enter the human body through air dust and drinking water, causing potential harm to human health ${ }^{[2-3]}$. Some of the emerging OPEs has been included in the list of POPs, which can be rapidly degraded in the body to produce polar, hydrophilic metabolites and excreted through urine. Some studies have determined organophosphate metabolites in urine samples ${ }^{[4-6]}$. $\mathrm{Lu}$ et al. ${ }^{[5]}$ found Bis(2-chloroethyl) phosphate [BCEP] was the most abundant $\mathrm{Cl}-\mathrm{mOP}$, and diphenyl phosphate (DPHP, $0.55 \mathrm{ng} / \mathrm{mL}$ ) was the most abundant $\mathrm{NCl}-\mathrm{mOP}$. University of Queensland in Australia have detected OPEs in urine and conducted a study of exposure routes ${ }^{[7]}$. Most of analyzing procedure include the derivatization which was quite complicated and lower recovery due to the low derivative efficiency.

This study intends to establish the relative simple quantitative analyzing method to detect the OPEs in urine. Later we could provide scientific support for the health risk assessment of the population by detecting the concentration of OPEs and its metabolites in urine of different age groups of people.

\section{Materials and methods}

Sample collection. Samples were collected in two batches, two samples each time, three of the students' mixed urine samples (2.0 L), numbered samples 1-1, samples 1-2, samples 2-1, samples 


\section{$2-2$.}

Instruments and reagents. The main instruments include vacuum concentrator (R-215/V-700, Swiss Bu Qi), gas chromatography-mass spectrometry (QP2010puls type, Japanese SHIMADZU) and thermostat box. The main reagents include acetone, ethyl acetate, n-hexane, acetonitrile and dichloromethane, which are all the HPLC purity; $\mathrm{HCl}$, anhydrous $\mathrm{Na}_{2} \mathrm{SO}_{4}, \mathrm{NaCl}, \mathrm{K}_{2} \mathrm{CO}_{3}$ (analytical purity), five fluorobrombenzyl benzene $\left(\mathrm{C}_{7} \mathrm{H}_{2} \mathrm{BrF} 6 \mathrm{PFBBr}\right)$ (purity 99\%), ether, methyl tert butyl ether (analysis pure); Seven organophosphate esters standard (Sigmaaldrich) including tri-n-butyl phosphate (TnBP), tris(2-ethylhexyl) phosphate (TEHP), tributoxyethyl phosphate (TBEP), triphenyl phosphate (TPhP), tri(2-chloroethyl) phosphate (TCEP), trichloropropyl phosphate (TCPP) and tridichloropropyl phosphate (TDCPP); $0.45 \mu \mathrm{m}$ filter membrane.

\section{Method exploration}

Derivation. Derivatization is a method of transforming compound into a relative compound that can be directly determined by instruments using derivatization agents. In this study, the derivative process are as follows: the urine sample $5.0 \mathrm{~mL}$ in the tube was added $8 \mathrm{~g} \mathrm{NaCl}, 2 \mathrm{~mL} \mathrm{HCl}$ $(6 \mathrm{~mol} / \mathrm{L}), 10 \mathrm{~mL}$ ether, ultrasonic extracted for $30 \mathrm{~min}, 10 \mathrm{~mL}$ methyl tert butyl ether was added and repeat the above steps. Then $10 \mathrm{~mL}$ ethyl acetate was added and repeat ${ }^{[5]}$. Finally, all organic phases were combined and concentrated to $200 \mu \mathrm{L}$, diluted with acetonitrile to $1 \mathrm{~mL}$. Adding $10 \mathrm{mg}$ $\mathrm{K}_{2} \mathrm{CO}_{3}$, a small amount of anhydrous $\mathrm{Na}_{2} \mathrm{SO}_{4}, 100 \mu \mathrm{L}$ derivatization reagent and 7 mixed standard solutions of $100 \mu \mathrm{L}(5 \mathrm{ppm})$. Then, it was kept for $16 \mathrm{~h}$ at $60^{\circ} \mathrm{C}$, and the upper solution $200 \mu \mathrm{L}$ was selected for GC /MS detection.

Selection of the conditions for derivatization was as following: according to the reports, the derivative reaction should be carried out for $16 \mathrm{~h}$ at $60^{\circ} \mathrm{C}$. In addition of this reaction condition, the following adjustment has been made: $24 \mathrm{~h}$ at $60^{\circ} \mathrm{C} ; 8 \mathrm{~h}$ at $80^{\circ} \mathrm{C}$. Results showed that under the above mentioned derivatization conditions, only a small amount of OPEs derivatives could be detected, which were lower than the limit of quantification. These results indicated that the derivatization efficiency was not high enough and the repeatability was poor, so the derivative reaction was not adopted.

Filtration. The following two cases were examined: (1) $200 \mathrm{~mL}$ urine samples were directly purified by activated HC-C18 column. The elution was concentrated to $200 \mu \mathrm{L}$ for GC-MS analysis. (2) The urine samples were filtered through $0.45 \mu \mathrm{m}$ waterborne membrane, sealed and stored; the separation and purification process was the same as above. The results showed that the fine particles in the urine could be removed effectively by filtration, and the operability of subsequent experiments was improved. Therefore, the follow-up experiments were performed by filtration.

Selection of sample dose. The above procedure was repeated for urine samples of $200 \mathrm{~mL}$, $500 \mathrm{~mL}, 800 \mathrm{~mL}, 1 \mathrm{~L}$ and $2 \mathrm{~L}$. The results showed that when the amount of sample was too small, the OPEs content was lower than the quantitative limit. Therefore, it is recommended to collect urine more than $2 \mathrm{~L}$ when possible.

Selection of elution solvent. According to the principle of similar phase dissolution, references and previous experience in the laboratory, the elution solvent was selected as a mixture of ethyl acetate and acetone, and the extraction effect of different solvent proportions were showed in Table 1. Finally, the elution solvent used in this experiment was a mixture solution of ethyl 
acetate: acetone ( $\mathrm{V}: \mathrm{V}=3: 2)$.

Table 1 Recovery of blank plus standard under different elution solvent

\begin{tabular}{|c|c|c|}
\hline & ethyl acetate: acetone $3: 2$ & ethyl acetate: acetone $4: 3$ \\
\hline TnBP & $72.47 \%$ & $65.80 \%$ \\
\hline TCEP & $82.10 \%$ & $68.16 \%$ \\
\hline TCPP & $71.32 \%$ & $62.37 \%$ \\
\hline TDCPP & $87.21 \%$ & $54.34 \%$ \\
\hline $\mathrm{TPhP}$ & $98.60 \%$ & $80.10 \%$ \\
\hline TBEP & $85.61 \%$ & $55.61 \%$ \\
\hline TEHP & $77.70 \%$ & $65.77 \%$ \\
\hline
\end{tabular}

It can be seen from the table that the recoveries of the 7 OPEs measured by this method were between $71.32 \%$ and $98.60 \%$, and this method is feasible.

Instrumental Analysis. The analysis was performed on GC-MS, RTI-5MS (30 $\mathrm{m} \times 0.25 \mu \mathrm{m} \times 0.25$ $\mathrm{mm}$ ). The GC oven temperature program was set at $50.0{ }^{\circ} \mathrm{C}$, hold for 1 minute, ramped $15.00{ }^{\circ} \mathrm{C} /$ min to $200.0{ }^{\circ} \mathrm{C}(1$ minute $)$, ramped at $2.00{ }^{\circ} \mathrm{C} / \mathrm{min}$ to $250{ }^{\circ} \mathrm{C}$, ramped $10.0{ }^{\circ} \mathrm{C} / \mathrm{min}$ to $260{ }^{\circ} \mathrm{C}(4$ minutes $)$.

The standard curve. The mixed standard solution of $2.00 \mathrm{mg} / \mathrm{L}$ was prepared, and the mixed solution was diluted to $0.05,0.10,0.50,1$, and $2.00 \mathrm{mg} / \mathrm{L}$ by $\mathrm{n}$-hexane. The correlation coefficient (r) of each OPEs component was higher than 0.99 which means the accuracy of the method was good.

\section{Sample test results and discussion}

Levels of seven kinds of OPEs in urine. Take $2 \mathrm{~L}$ urine for each batch and make a parallel sample. The concentration range of $\sum 7 \mathrm{OPEs}$ was between $44.41 \mathrm{ng} / \mathrm{L} \sim 644.73 \mathrm{ng} / \mathrm{L}$. In sample 1-1 and sample 1- 2, the $\sum 70 P E s$ was low, $59.61 \mathrm{ng} / \mathrm{L}$ and $44.41 \mathrm{ng} / \mathrm{L}$, respectively, while the concentrations of $\sum 7 \mathrm{OPEs}$ in sample 2-1 (644.73ng/L) and 2- $2(421.18 \mathrm{ng} / \mathrm{L})$ were relatively high. It can be seen that the contents of OPEs in urine were quite different in the same sample source but in different time. It may be caused by different dietary and metabolic levels of individuals at different times, and may also be related to environmental factors.

The distribution of OPEs in urine. The concentrations of OPE monomers in urine were shown in Fig.1. The OPEs monomers detected in urine samples were TnBP, TCEP, and TBEP, while TCEP, TDCPP, TPhP and TEHP were not detected. The TCEP content in sample 1-1 was the highest, accounting for $80 \%$ of the total, while TBEP was not detected. The content of TCEP in sample 1-2 was the highest, followed by TnBP, accounting for $56 \%$ and $40 \%$ of the total, respectively. The content of monomers in samples 2-1 and 2-2 OPEs was in the trend of $\operatorname{TBEP}(68 \%)>\operatorname{TnBP}(30 \%)>\operatorname{TCEP}(2 \%)$. The content of the OPEs monomer in the same batch were similar, so the experimental operation has a good parallelism. 


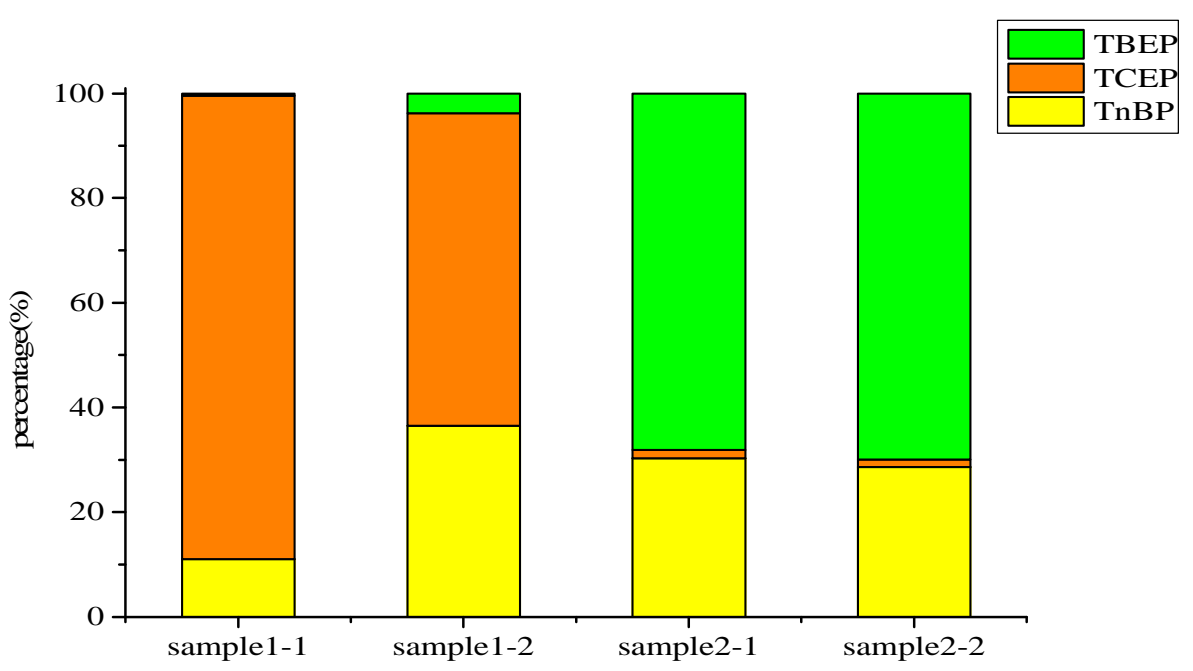

Fig. 1 Distribution of OPEs in urine

According to the results of 400 children's urine samples analyzed by University of Queensland, the content of TnBP was the dominant OPE monomer, which was obviously higher than that in our samples. The highest OPEs content of our urine samples was observed in TBEP, which was greater than that by University of Queensland. Concentrations of TCEP in our samples were less than them. These differences reflect that under different levels of socio-economic development, the sources and degrees of OPEs pollution in human were significantly different.

\section{Conclusions.}

A method for the quantitative determination of seven kinds of OPEs in urine byGC-MS was established and optimized. The concentration rang of 7OPEs in human urine was $44.41 \mathrm{ng} / \mathrm{L} \sim 644.73 \mathrm{ng} / \mathrm{L}$. Influenced by factors such as diet condition, body metabolism and environmental quality, the distribution of 7OPEs in urine samples were obviously different.

\section{Acknowledgements}

This work was financially supported by financial support from the National Natural Science Fund (21407014, 326 41773072), the Key Laboratory Fund for Atmospheric Pollution Control and Environmental Simulation of Chengdu University of Information Technology (No.KFKT2016001).

\section{References}

[1] X.W. Wang, J.F. Liu, Y.G. Yin: Prog. Chem., 2010, 22(10): 1983- 1992.

[2] W.M. Grant: Thomas Publisher, 1974.

[3] E, Bingham, B. Cohrssen, C.H. Powell: New York: John Wiley and Sons, 2001.

[4] S.Y. Lu, Y.X. Li, T. Zhang, et al: Environ. Sci. Techno., 2017, 51 (4): 2427-2437.

[5] E.Cequier, R.M. Marcé, G. Becher, et al : Analytica Chimica Acta, 2014, 845:98-104.

[6] M.Y. Huang, N.Wang, X.Y. Guo, et al: Chinese Journal of Analytical Chemistry, 2016, 44(5): 723-730. 
[7] dE.N.Van, A.L.Heffernan, Aylward L L, et al: Environment International, 2015, 74(8):1-8. 